\title{
Not-for-profit hospitals' provision of community benefit during the 2008 recession: An analysis of hospitals in Maryland
}

\author{
Simone Rauscher Singh \\ School of Public Health, University of Michigan, Ann Arbor, USA \\ Correspondence: Simone Singh. Address: School of Public Health, University of Michigan, Ann Arbor, MI 48109, USA. \\ Email: singhsim@umich.edu \\ Received: October 28, 2013 \\ DOI : $10.5430 /$ jha.v3n3p7 \\ Accepted: December 9, $2013 \quad$ Online Published: December 17, 2013 \\ URL: http://dx.doi.org/10.5430/jha.v3n3p7
}

\begin{abstract}
During the 2008 recession, many U.S. hospitals had to lay off staff and cut services to reduce costs, yet little is known about how these cuts affected hospitals' provision of community benefits. While the need for charitable programs and services grew during this economically difficult time, financial pressures may have forced hospitals to cut back on their community benefit spending. Using data for not-for-profit hospitals in the state of Maryland for the years 2006 to 2010, this study explored whether, and if so how, hospitals changed their provision of community benefit during the 2008 recession. The findings showed that, on average, Maryland hospitals increased their charitable activities during the recent recession. Between 2006 and 2010, total spending on community benefits grew from an average of 5.6\% to 7.7\% of operating expenses with the most substantial growth in hospitals' provision of charity care and mission-driven health services. Panel regression analysis showed that this increase in charitable activity was associated with increases in community need. Hospitals' financial performance, on the other hand, was unrelated to their community benefit spending. These findings indicate that even in times of constrained budgets, Maryland hospitals provided substantial amounts of community benefit in response to the needs of the communities they serve. Hospital-based community benefit programs thus have the potential to play an important role in on-going community-wide efforts aimed at reducing the burden of illness and improving population health.
\end{abstract}

\section{Key words}

Community benefit, Community need, Hospital financial performance, Not-for-profit hospitals

\section{I ntroduction}

During the 2008 recession, many U.S. hospitals were forced to lay off staff and cut services to reduce costs ${ }^{[1,2]}$, yet little is known about how these cuts affected hospitals' provision of community benefits. Rising unemployment rates during the recession combined with the loss of employer-sponsored health insurance coverage may have increased the demand for free and reduced cost health care, an important component of most hospitals' community benefit programs. At the same time, financial pressures may have forced hospitals to cut their community benefit budgets and thus reduce the amount of charitable activities provided to the community. 
While most U.S. hospitals engage in some community benefit activities, under current tax law, not-for-profit hospitals exempt under Section 501(c)(3) of the Internal Revenue Code are required to do so to maintain their federal tax-exempt status. Since 2009, these hospitals have been mandated to complete Form 990 Schedule $\mathrm{H}$ to submit detailed information on their community benefit activities to the Internal Revenue Service (IRS). In addition, a number of states require hospitals to complete community benefit reports for the purpose of exemption from state and local taxes ${ }^{[3,4]}$. Neither the IRS nor the majority of states, however, requires not-for-profit hospitals to meet minimum spending thresholds to remain tax-exempt. Since most community benefit activities generate low or negative financial returns, hospital managers may thus consider them easy targets for cost reductions. Scaling back or discontinuing programs during financially difficult times, such as the 2008 recession, may have allowed hospitals to reduce their operating expenses and improve their financial position without losing their tax exemptions.

Little is known currently about whether, and if so how, not-for-profit hospitals changed their provision of community benefits during the 2008 recession. Did hospitals that experienced greater demand for community benefit increase their charitable spending despite financial pressures? Or did poor financial performance force hospital managers to reduce their community benefit budgets? This study aims to shed light on these questions using community benefit data from hospitals in the state of Maryland. Unlike most U.S. states, Maryland has had a community benefit reporting requirement similar to the recently implemented federal reporting requirement (i.e., IRS Form 990 Schedule H) since 2004. While unique in many ways, Maryland thus offers longitudinal data that provides an opportunity to study hospitals' charitable activities before, during, and after the 2008 recession.

For health managers and policymakers this study provides some insight into whether, and if so how, hospitals changed their community benefit spending during a recent period of increased financial pressures. Hospitals' community benefit programs and services fill critical health needs in the communities they serve. An in-depth understanding of the factors that impact hospitals' charitable spending may allow all community stakeholders - including hospitals, local health departments, employers, insurers, and non-profit organizations - to better coordinate their activities. Community-wide collaboration has the potential to establish effective, non-redundant initiatives to reduce the burden of illness in a community and improve the health of all its residents.

\section{The impact of the 2008 recession on not-for-profit hospitals in the U.S.}

According to the National Bureau of Economic Research, the 2008 recession started in December 2007 and ended in June 2009. During this time, GDP contracted and unemployment rates doubled. By 2010, a recovery of the U.S. economy was at least partially underway. However, growth was still slow and unemployment rates remained high.

Like most other sectors of the U.S. economy, the hospital industry was greatly impacted by the 2008 recession. Rising unemployment resulted in substantial losses of employer-sponsored health insurance and rising numbers of uninsured individuals and families ${ }^{[5]}$. Only a minority of these newly uninsured qualified for coverage under public programs, such as Medicaid and the State Children's Health Insurance Program (SCHIP). A majority remained without insurance coverage. In addition, higher unemployment reduced family incomes and thus the resources these families were able to dedicate to health care, leading many to delay non-urgent medical services.

The results of these changes for hospitals were twofold. First, hospitals experienced reductions in patient volumes, particularly for elective procedures, many of which are among the most profitable services hospitals provide ${ }^{[6]}$. Second, hospitals experienced changes in payer mix. As the number of patients with private insurance coverage decreased and the number of patients with low-reimbursing insurers (e.g., Medicaid and SCHIP) or no coverage at all increased, hospitals' average reimbursement per patient dropped ${ }^{[7]}$. Reductions in patient volumes combined with changes in payer mix markedly lowered hospitals' patient care revenues and subsequently their profit margins ${ }^{[8]}$. 
At the same time, as a result of the financial crisis that led to the 2008 recession, many not-for-profit hospitals experienced substantial reductions in their non-operating revenues, in particular their income from financial investments ${ }^{[9]}$. The crash of the stock market in 2008 dramatically reduced the value of hospitals' financial investment portfolios. As a result, hospitals' non-operating income took a big hit. Traditionally, financial investments have represented an important component of hospitals' overall profitability and allowed many hospitals to at least partially offset any losses incurred from providing patient care ${ }^{[10-12]}$. During the recession, these cash flows all but disappeared.

In response to these financial pressures, many hospitals were forced to reduce non-profitable services and lay off staff to cut costs and remain financially viable. Little is known currently, however, about how these cuts affected hospitals' provision of community benefit. One of the few empirical studies in this area, a descriptive analysis of 15 large, not-for-profit health systems, found that total community benefit spending increased between 2007 and $2008{ }^{[13]}$. The findings of this study, however, are limited given its small sample and focus on only two years of data. Moreover, the study was unable to distinguish among various categories of community benefit spending and thus did not examine whether there were differences between hospitals' provision of free and reduced cost care and their spending on programs and services that benefit the health of the community at large thus leaving many questions around hospital charitable activity during financially difficult times unanswered.

\section{Methods}

\subsection{Data and sample}

Data for this study came from Maryland hospitals' state-level community benefit reports. Since 2004, not-for-profit hospitals in Maryland have been required to report annually to the state's Health Services Cost Review Commission on a defined set of community benefit activities in a format similar, but not identical to, the recently revised IRS Form 990 Schedule H. As a result, Maryland is one of the few states for which community benefit expenditure information is available in a consistent format for years prior to 2009, when federal community benefit reporting took effect. The sample for this study included 47 Maryland hospitals. With the exception of one for-profit institution, all hospitals in the state of Maryland are not-for-profit organizations. The time frame examined was the period before, during, and after the 2008 recession, more specifically the years 2006 to 2010.

\subsection{Dependent variables}

Maryland's community benefit reporting law requires that hospitals provide detailed financial information on a broad range of community benefit activities. Categories that hospitals are asked to report on include charity care, mission-driven health services, community health services, health professions education, research, community building activities, financial contributions made by the hospital, as well as any community benefit activities funded by a hospital's foundation. The reports also require hospitals to provide information on the costs of operating their community benefit programs. Except for charity care, which Maryland hospitals report at full prices, all community benefit activities are reported in terms of the net unreimbursed costs to the hospital of providing the benefit, i.e., costs minus any offsetting revenues, such as fee-for-service payments and grant support. Following these reporting requirement, for the purpose of this study, charity care was measured at full prices (not adjusted for subsidies) while all other community benefit activities were measured at net unreimbursed costs.

The analysis focused on charity care, mission-driven health services, community health services, and health professions education, which together accounted for approximately 95\% of Maryland hospitals' community benefit spending. Charity care represents hospital services provided to patients who are unable to pay for care and who qualify for free treatment under the hospital's charity care policy. Mission-driven health services are expenditures for services that are generally not or only inadequately reimbursed but are offered as a result of the hospital's mission. Examples include outpatient mental 
health programs, home health care, hospice, and programs targeted to specific vulnerable populations, such as pregnant women, seniors, immigrants, substance abusers, and the homeless. Community health services include the costs for community health education activities, community-based clinical services, and health care support services. Examples include screening and immunization programs, free clinics, lectures, health fairs, and patient support groups. Health professions education represents the costs associated with educating and training health professionals. In addition to graduate medical education for physicians, this includes nurses and allied health professionals.

Unlike IRS Form 990 Schedule H, Maryland's community benefit reporting requirement does not ask hospitals to report on Medicaid and other government payer shortfalls. The reason for this is that in Maryland, the state's Health Services Cost Review Commission regulates hospital payment rates for all third-party payers, including Medicare and Medicaid. All third-party payers pay a hospital the same rates so that, by definition, Maryland hospitals do not experience government payer payment shortfalls thus relieving hospitals of much of the financial burden of treating publicly insured patients.

\subsection{I ndependent and control variables}

Independent variables of interest for this study included indicators of community need for hospitals' community benefit services and indicators of hospitals' financial status. We chose two indicators of community need - county-level all-age poverty rates and percent of non-elderly uninsured residents. We chose these two indicators because they are fairly responsive to changes in economic conditions and thus good proxies for the increasing health needs of a community during economically difficult times, such as the 2008 recession. Data for both variables was obtained from the Census. We also chose two indicators of hospital financial performance - operating margin and non-operating income ${ }^{[14]}$. Operating margin, i.e., profitability from providing patient care and related services, was defined as a hospital's operating income divided by its operating revenues. Non-operating income, i.e., income from non-patient care activities, was defined as a hospital's non-operating income divided by its net income. Both operating margin and non-operating income were calculated using data obtained from Maryland hospital's community benefit reports.

Since this study used a panel regression approach the number of additional control variables that can be included in the analysis was limited. Prior studies have found that the charitable activities of other hospital providers in a market affected a hospital's spending on community benefit ${ }^{[15]}$. We therefore included the total dollar amount of community benefits provided by other hospitals in the county divided by the total dollar amount of community benefits provided by the hospital itself as a control variable. In addition, we included year dummies to account for changes in community benefit reporting requirements over time. In 2009, not-for-profit hospitals across the U.S. were required, for the first time, to report in detail on their community benefit activities on the revised IRS Form 990 Schedule H. This new reporting requirement resulted in renewed interest in hospitals' community benefit activities and may thus have led hospitals to increase their provision of charitable activities or, at the least, improve their reporting of community benefit expenditure information. Even though Maryland had a similar reporting requirement since 2004, hospitals in Maryland may have started to pay closer attention to their community benefit spending when the revised federal reporting requirement took effect.

\subsection{Analytical approach}

This study used a multivariate regression approach to explore whether, and if so how, Maryland hospitals' community benefit expenditures changed during the 2008 recession. We modeled the provision of community benefit (CommBen) for hospital $i$ at time $t$ as a function of the need (Need) for community benefits in the community the hospital serves, controlling for the financial situation (Fin) of the hospital. Formally, we estimated regressions based on the following specification:

$$
\text { CommBen }_{i t}=\beta_{1} \text { Need }_{i t}+\beta_{2} \text { Fin }_{i t}+\beta X_{i t}+\mu_{i}+\varepsilon_{i t}
$$


where $X_{i t}$ is a vector of additional control variables, $\mu_{i}$ is the hospital-specific fixed or random effect, and $\varepsilon_{i t}$ is the hospital-specific error term. The parameters $\beta_{1}$ and $\beta_{2}$ capture the change in hospital $i$ 's community benefit provision with respect to changes in the need for community benefit and its financial situation, respectively. Since hospitals' community benefit expenditures are highly skewed we used the natural logarithm of hospitals' expenditures as our dependent variables. We estimated the model separately for all sub-categories of community benefits as well as total community benefit spending. Hausman tests were used to decide whether to include fixed or random effects in our models (for results, see Table 3).

\section{Results}

\subsection{Maryland hospitals' community benefit spending during the 2008 recession}

During the recent economic downturn, Maryland hospitals' spending on community benefits increased substantially. Between 2006 and 2010, aggregate community benefit spending grew from a total of \$718 million in 2006 to over \$1 billion in 2010. As a result, average spending rose from 5.6\% of operating expenses in 2006 to $7.7 \%$ in 2010 (see Table 1). For the typical hospital, total community benefit expenditures thus increased by over $25 \%$ during this time. However, Maryland hospitals' spending did not increase uniformly across all categories of community benefit activities (see Table 1). Spending on charity care and mission-driven health services increased the most, while all other community benefit programs saw comparatively small increases.

Table 1. Provision of community benefit as a percentage of Maryland hospitals' operating expenses

\begin{tabular}{lllllll}
\hline Community benefit & & $\mathbf{2 0 0 6}$ & $\mathbf{2 0 0 7}$ & $\mathbf{2 0 0 8}$ & $\mathbf{2 0 0 9}$ & $\mathbf{2 0 1 0}$ \\
\hline \multirow{2}{*}{ Charity care } & Mean & 2.0 & 2.1 & 2.2 & 2.5 & 2.9 \\
& Interquartile range & $1.0-2.5$ & $1.1-2.8$ & $1.2-3.0$ & $1.3-3.4$ & $1.6-4.0$ \\
\multirow{2}{*}{ Mission-driven health services } & Mean & 1.4 & 1.7 & 1.8 & 1.8 & 2.3 \\
& Interquartile range & $0.1-2.1$ & $0.4-2.2$ & $0.6-2.3$ & $0.5-2.4$ & $0.6-3.3$ \\
\multirow{2}{*}{ Community health service } & Mean & 0.5 & 0.6 & 0.5 & 0.6 & 0.7 \\
\multirow{2}{*}{ Health professions education } & Interquartile range & $0.2-0.7$ & $0.2-0.8$ & $0.2-0.8$ & $0.2-0.8$ & $0.2-0.7$ \\
& Mean & 1.4 & 1.3 & 1.2 & 1.4 & 1.5 \\
\multirow{2}{*}{ All community benefits } & Interquartile range & $0.1-2.7$ & $0.1-2.7$ & $0.1-2.7$ & $0.1-2.7$ & $0.2-2.5$ \\
& Mean & 5.6 & 6.1 & 6.2 & 6.7 & 7.7 \\
\hline
\end{tabular}

\subsection{Variation in Maryland hospitals' community benefit spending during the 2008 recession}

The amount of resources Maryland hospitals spent on community benefits varied widely (see Table 1). In 2010, total spending on all community benefit activities ranged from a minimum of $1.3 \%$ of operating expenses to a maximum $17.1 \%$. Much of this variation occurred because two of the three largest categories of community benefit spending - charity care and health professions education - were concentrated in only a few hospitals. Between 2006 and 2010, the variation in community benefit spending across hospitals increased. While there were no significant changes in the minimum amounts that hospitals spent on community benefit activities, maximum spending in almost all categories increased. Maximum spending on charity care, for instance, grew from 6.3\% of operating expenses in 2006 to $7.3 \%$ in 2010. Likewise, maximum spending on mission-driven health services increased from 9.3\% in 2006 to $10.1 \%$ in 2010. 


\subsection{The role of community need in hospitals' provision of community benefit during the 2008 recession}

Between 2006 and 2010, poverty rates in Maryland increased from an average of 10.7\% to 13.4\% (see Table 2). The share of non-elderly uninsured residents, on the other hand, decreased from $15.5 \%$ to $13.5 \%$ during this time period. Given these trends, our multivariate regression analysis generally found positive relationships between poverty rates and hospitals' provision of most community benefits and negative relationships between uninsured rates and hospitals' provision of most community benefits (see Table 3). While in the expected directions, many of these relationships were only marginally statistically significant. Our analysis of hospitals' total community benefit spending, for instance, showed that changes in the number of non-elderly uninsured residents were associated with changes in community benefit provision, yet the positive association between changes in poverty rates and changes in community benefit provision was not statistically significant.

Table 2. Community need and hospital financial performance

\begin{tabular}{lllllll}
\hline Variable & & $\mathbf{2 0 0 6}$ & $\mathbf{2 0 0 7}$ & $\mathbf{2 0 0 8}$ & $\mathbf{2 0 0 9}$ & $\mathbf{2 0 1 0}$ \\
\hline Community need & & & & & \\
All-age poverty rate & Mean & 10.7 & 11.3 & 11.1 & 12.2 & 13.4 \\
& Interquartile range & $4.8-19.2$ & $5.6-19.9$ & $5.8-19.2$ & $6.7-20.9$ & $7.5-24.7$ \\
$\begin{array}{l}\text { Percent of non-elderly } \\
\text { uninsured }\end{array}$ & Mean & 15.5 & 14.7 & 13.3 & 13.9 & 13.5 \\
Hospital financial performance & Interquartile range & $14.0-17.0$ & $12.9-14.7$ & $11.0-15.2$ & $11.9-16.4$ & $12.1-15.7$ \\
\multirow{2}{*}{ Operating margin } & Mean & 2.6 & 2.4 & & & \\
& Interquartile range & $1.0-4.4$ & $0.9-4.7$ & $0.4-4.6$ & 1.4 & 2.4 \\
\multirow{2}{*}{ Non-operating margin } & Mean & 1.3 & 1.8 & 0.3 & -3.3 & $0.6-4.6$ \\
& Interquartile range & $0.3-2.5$ & $0.5-3.2$ & $-0.4-1.4$ & $-4.6-0.1$ & $0.1-2.3$ \\
\hline
\end{tabular}

\subsection{The role of hospitals' financial status in hospitals' provision of community benefit during the 2008 recession}

Maryland hospitals' financial performance took a big hit during the 2008 recession (see Table 2). Operating margins declined to an average of $1.8 \%$ in 2008, down from an average of $2.6 \%$ in 2006. By 2009, however, operating margin had recovered and reached pre-recession levels. Hospitals' non-operating income experienced a steeper and longer-lasting decline. In 2008, average non-operating income was just $0.3 \%$ of net income, down from $1.8 \%$ in 2007. In 2009, non-operating income dropped even further to an average of negative 3.3\% before returning to pre-recession levels in 2010. Despite these variations in hospitals' financial performance, our multivariate regression analysis found no statistically significant relationships between the financial indicators studied and hospitals' provision of community benefits (see Table 3). The only borderline significant relationship we found was between operating margin and hospitals' provision of health professions education whereby higher operating margins were associated with higher spending. For the provision of all other community benefits, hospitals' financial performance did not matter.

\subsection{The role of neighboring providers' community benefit activities in hospitals' provision of community benefit during the 2008 recession}

Besides community need, a strong predictor of whether Maryland hospitals increased their community benefit spending during the recent recession was the charitable activity of neighboring providers (see Table 3). Changes in hospitals' spending on charity care and mission-driven health services, in particular, frequently occurred in response to changes in the spending by other providers in a community. The more resources other providers in a county committed to charitable activities, the less Maryland hospitals spent on charity care and mission-driven health services. Hospitals may thus take into account the resources already available in a community when making decisions about their own community benefit spending. 
Table 3. Relationship between community need, hospital financial performance and hospitals’ provision of community benefits

\begin{tabular}{|c|c|c|c|c|c|}
\hline & Charity care & $\begin{array}{l}\text { Mission driven } \\
\text { health services }\end{array}$ & $\begin{array}{l}\text { Community } \\
\text { health services }\end{array}$ & $\begin{array}{l}\text { Health professions } \\
\text { education }\end{array}$ & $\begin{array}{l}\text { All community } \\
\text { benefits }\end{array}$ \\
\hline All-age poverty rate & $\begin{array}{l}0.080 * * \\
(0.002)\end{array}$ & $\begin{array}{l}0.14 * * \\
(0.005)\end{array}$ & $\begin{array}{l}0.054 \\
(0.086)\end{array}$ & $\begin{array}{l}0.086 \\
(0.11)\end{array}$ & $\begin{array}{l}0.024 \\
(0.16)\end{array}$ \\
\hline $\begin{array}{l}\text { Percent of non-elderly } \\
\text { uninsured }\end{array}$ & $\begin{array}{l}-0.077 * * \\
(<0.001)\end{array}$ & $\begin{array}{l}-0.096^{*} \\
(0.005)\end{array}$ & $\begin{array}{l}-0.047 \\
(0.068)\end{array}$ & $\begin{array}{l}0.027 \\
(0.54)\end{array}$ & $\begin{array}{l}-0.063^{* *} \\
(<0.001)\end{array}$ \\
\hline Operating margin & $\begin{array}{l}-1.23 \\
(0.28)\end{array}$ & $\begin{array}{l}-1.65 \\
(0.50)\end{array}$ & $\begin{array}{l}0.091 \\
(0.95)\end{array}$ & $\begin{array}{l}5.99 * \\
(0.021)\end{array}$ & $\begin{array}{l}0.41 \\
(0.52)\end{array}$ \\
\hline Non-operating income & $\begin{array}{l}-0.45 \\
(0.55)\end{array}$ & $\begin{array}{l}1.23 \\
(0.41)\end{array}$ & $\begin{array}{l}0.0051 \\
(0.99)\end{array}$ & $\begin{array}{l}-0.36 \\
(0.88)\end{array}$ & $\begin{array}{l}0.44 \\
(0.30)\end{array}$ \\
\hline $\begin{array}{l}\text { Community benefits } \\
\text { provided by other } \\
\text { hospitals }\end{array}$ & $\begin{array}{l}-0.020 * * \\
(<0.001)\end{array}$ & $\begin{array}{l}-0.056 \\
(<0.001)\end{array}$ & $\begin{array}{l}-0.011 \\
(0.14)\end{array}$ & $\begin{array}{l}-0.00087 \\
(0.94)\end{array}$ & $\begin{array}{l}-0.020 * * \\
(<0.001)\end{array}$ \\
\hline $\begin{array}{l}\text { Hausman test statistic } \\
\text { and } p \text {-value }\end{array}$ & $\begin{array}{l}10.82 \\
(.21)\end{array}$ & $\begin{array}{l}3.90 \\
(.87)\end{array}$ & $\begin{array}{l}9.71 \\
(.29)\end{array}$ & $\begin{array}{l}12.74 \\
(.12)\end{array}$ & $\begin{array}{l}382.95 * * \\
(<.001)\end{array}$ \\
\hline $\begin{array}{l}\text { Fixed (FE)/random } \\
\text { (RE) effects included }\end{array}$ & $47 \mathrm{RE}$ included & $47 \mathrm{RE}$ included & $47 \mathrm{RE}$ included & $47 \mathrm{RE}$ included & $47 \mathrm{FE}$ included \\
\hline $\mathrm{R}^{2}$ within & 0.34 & 0.13 & 0.06 & 0.06 & 0.52 \\
\hline $\mathrm{R}^{2}$ overall & 0.30 & 0.12 & 0.15 & 0.20 & 0.03 \\
\hline
\end{tabular}

Note. Table displays regression coefficients with p-values in parentheses. * indicates statistically significant at the five percent confidence level. ** indicates statistically significant at the one percent confidence level. Hausman test statistic displays chi-squared values with p-values in parentheses.

\section{Discussion}

Despite substantial financial pressures, Maryland hospitals increased their provision of community benefit during the 2008 recession. Between 2006 and 2010, average spending on community benefits increased from $5.6 \%$ to $7.7 \%$ of operating expenses with most of the growth occurring in charity care and mission-driven health services. Greater need during difficult economic times undoubtedly played an important role in hospitals' increased spending. As the share of people living in poverty increased, more patients qualified for charity care under hospitals' charity care policies resulting in higher expenses for many hospitals. In addition, in Maryland, higher charity care spending is often directly linked with higher expenditures on mission-driven health services as the mission-driven category includes, among other items, hospitals' payments to physicians for professional services to charity patients ${ }^{[16]}$.

Hospitals' financial performance during the 2008 recession, on the other hand, was unrelated to their community benefit spending. Neither reduced operating margins nor declining non-operating profitability had an effect on the levels of community benefit provided by hospitals in Maryland. This lack of a relationship between financial performance and community benefit spending suggests that not-for-profit hospitals' provision of community benefit may not be sensitive to short-term changes in hospital profitability. Consistent with prior empirical evidence ${ }^{[17]}$, these findings provide support for the idea that hospitals' investment in community benefits are prioritized over other possible investment opportunities in times of reduced income. When faced with greater need, many Maryland hospitals even were in the position to increase their spending on community benefit activities.

Another explanation for the lack of a relationship between financial performance and community benefit spending, however, may be that Maryland hospitals are to some extent shielded from the true costs of increased community benefit spending. Maryland is one of the few U.S. states that operate all-payer rate-setting systems. More specifically, in Maryland, the state's Health Services Cost Review Commission regulates hospital payment rates for all third-party payers, including public payers such as Medicare and Medicaid. The costs of charity care - an important component of most 
hospitals' community benefit activities - are built into the overall rates at which hospitals are reimbursed for services provided. Charity care costs are thus, in essence, "passed-through" to all payers ${ }^{[18]}$. As a result, despite financial pressures, hospitals in Maryland face less of a financial disincentive to provide charity care and may be in a stronger financial position to increase their provision of such care in times of high need than hospitals in other states.

While changes in community need during the 2008 recession were found to be strongly associated with changes in Maryland hospitals' provision of community benefits, the study design does not allow us to conclude that the recession is the true cause of the observed changes in hospitals' charitable spending. Rather, regulatory changes both at the state and the federal level may have contributed to hospitals' spending increases. In 2001, Maryland adopted a state-level community benefit reporting requirement for all not-for-profit hospitals ${ }^{[19]}$. Under this regulation, not-for-profit hospitals have been required since 2004 to report annually on their community benefit activities and expenditures. At the federal level, the IRS introduced more rigorous community benefit reporting requirements as part of its redesigned Form 990 Schedule H. Since 2009, not-for-profit hospitals across the U.S. have been required to provide detailed information on their community benefit activities as part of their annual tax return. Both reporting requirements have significantly increased transparency by allowing regulators and the public to directly compare the community benefit activities of Maryland hospitals. This increased scrutiny may have put pressure on hospitals with modest community benefit expenditures to dedicate additional resources to their charitable activities.

\section{Limitations}

This research has several limitations that may affect the findings and limit their generalizability. First, the study was limited to hospitals in Maryland, which is one of the few states that has required not-for-profit hospitals to report on their community benefit activity in a format similar to IRS Form 990 Schedule $\mathrm{H}$ before the federal reporting requirement took effect. Maryland, however, is unique in many respects. Unlike hospitals in most other states, Maryland hospitals operate under an all-payer rate-setting system, which relieves hospitals of much of the financial burden of treating publicly insured and uninsured patients. As a result, Maryland hospitals may be able to spend larger shares of their community benefit budgets on the health and well-being of the community than hospitals in other states ${ }^{[20-22]}$. In addition, since 2004 , Maryland hospitals have been required to report on their community benefit activities at the state level. This reporting requirement has heightened hospitals' awareness of the importance of their community benefit activity resulting in more resources being dedicated to such activities and improved reporting.

Second, following prior studies, we defined a hospital's community as the county it operates in. While the community a hospital serves likely differs from the county that the hospital is located in, data limitations prevented us from using a more refined approach. Hospitals in urban areas, for instance, tend to have service areas that comprise only a part of a city while hospitals in rural areas may serve multiple counties. The findings of this study may change if we had information on a hospital's true service area and the health needs of the community in the service area. In the future, some of the information may become available as part of the community health needs assessments that the IRS now requires all not-for-profit hospitals to conduct and report on. Additional research using a more refined definition of a hospital's community will thus be needed.

Third, our measures of hospital financial performance were limited to indicators of hospitals' operating and non-operating margins. While margins represent key financial performance indicators used by most hospital managers, in practice, margins are viewed alongside numerous other financial indicators, in particular measures of a hospital's free cash flow. The data we had available for this study, however, was limited thus preventing us from including additional financial indicators as control variables.

Forth, our study design cannot truly isolate the effect of either the 2008 recession or the new IRS community benefit reporting requirement. This problem is a fundamental one of before-and-after studies, such as the one presented in this 
paper. Since the recession was fairly uniform in onset and affected all U.S. states, we were unable to conduct a more sophisticated analysis using, for instance, a difference-in-difference approach. Likewise, since the new IRS reporting requirement affected all not-for-profit hospitals equally, a difference-in-difference analysis cannot be conducted to isolate the effect that the new requirement may have on the provision of community benefits. Some of the increase we observed in charitable activity may thus be the result of this new reporting requirement rather than changes in community need or hospital financial status.

Finally, our study design cannot rule out that some of the increase in community benefit spending during the study period may not represent actual increases in expenditures but rather the result of changes in hospitals' efforts to capture and document all of their community benefit activities. Compiling complete community benefit expenditure information can be challenging and the way it is done varies greatly among hospitals. Community benefit reporting requirements require hospitals to design and implement effective processes for capturing reportable community benefit activities ${ }^{[23]}$. Many hospitals, especially smaller hospitals with limited managerial capacity, experience a steep learning curve in the first several years of a reporting requirement as they improve their internal processes and study their competitors' community benefit reports to improve their own data collection and reporting efforts.

\section{Conclusion}

Maryland hospitals spend substantial resources on a wide variety of community benefit activities. Despite the difficult financial situation that many hospitals found themselves in during the 2008 recession, overall charitable spending by hospitals in Maryland increased significantly during this time. Even as their own financial performance took a hit, Maryland hospitals responded to the needs of their communities by providing substantial charitable programs and services. These findings are encouraging. In particular during times of economic downturns and tight government budgets, hospital-driven community benefit programs have the potential to complement the activities of other safety-net providers in a community ${ }^{[24,25]}$. Additional requirements for not-for-profit hospitals, such as the mandate contained in the Affordable Care Act (ACA) to conduct regular community health needs assessments, will provide further incentives for hospital to engage in multi-sector community partnerships when assessing community needs and designing community

benefit portfolios ${ }^{[26,27]}$. This renewed focus on hospitals' community benefit activities combined with the ACA requirements have the potential to establish effective, coordinated, and non-redundant community health initiatives designed to reduce the burden of illness in a community and improve population health.

\section{References}

[1] American Hospital Association. The impact of the economic crisis on health services for patients and communities. Washington, DC: American Hospital Association. 2009. Available from: www.aha.org/content/00-10/090311econcrisisdatabank.pdf

[2] American Hospital Association. Trendwatch: The economic downturn and its impact on hospitals. Washington, DC: American Hospital Association. 2009. Available from: www.aha.org/research/reports/tw/twjan2009econimpact.pdf

[3] Hellinger, F. J. Tax-exempt hospitals and community benefits: A review of state reporting requirements. Journal of Health Politics, Policy, and Law. 2009; 34: 37-61. PMid: 19234293. http://dx.doi.org/10.1215/03616878-2008-991

[4] Colombo, J. D., Griffith, G. R., King, J. M. Charity Care for Nonprofit Hospitals: A Legal and Administrative Guide. New York: Aspen Publishers. 2011.

[5] Kaiser Commission on Medicaid and the Uninsured. Changes in health insurance coverage in the Great Recession. 2007-2010. Washington, DC: Kaiser Commission on Medicaid and the Uninsured. Available from: http://kff.org/medicaid/issue-brief/changes-in-health-insurance-coverage-in-the/.

[6] American Hospital Association. The impact of the economic crisis on health services for patients and communities. Washington, DC: American Hospital Association. 2009. Retrieved from www.aha.org/content/00-10/090311econcrisisdatabank.pdf

[7] Sussman, J. B., Halasyamani, L.K., Davis, M.M. Hospitals during recession and recovery: Vulnerable institutions and quality at risk. Journal of Hospital Medicine. 2010; 5: 302-305. PMid: 20533580. http://dx.doi.org/10.1002/jhm.654 
[8] American Hospital Association. Trendwatch: The economic downturn and its impact on hospitals. Washington, DC: American Hospital Association. 2009. Available from: www.aha.org/research/reports/tw/twjan2009econimpact.pdf

[9] McCue, M. J. A descriptive analysis of the 2008 credit crisis on multistate healthcare systems: What impact did it have on their financial performance? Hospital Topics. 2010; 88: 53-60. PMid: 20494885. http://dx.doi.org/10.1080/00185861003768977

[10] Song, P. H., Smith, D. G., Wheeler, J. R. C. It was the best of times, it was the worst of times: A tale of two years in not-for-profit hospital financial investments. Health Care Management Review. 2008; 33: 234-242. PMid: 18580303. http://dx.doi.org/10.1097/01.HMR.0000324905.96401.f3

[11] Reiter, K. L., Song, P. H. The role of financial market performance in hospital capital investment. Journal of Health Care Finance. 2010; 37: 38-50.

[12] Singh, S. R., Song, P. H. Nonoperating revenue and hospital financial performance: Do hospitals rely on income from nonpatient care activities to offset losses on patient care? Health Care Management Review. 2013; 38: 201-210. PMid: 22713538. http://dx.doi.org/10.1097/HMR.0b013e31825f3e16

[13] McCue, M. J. A descriptive analysis of the 2008 credit crisis on multistate healthcare systems: What impact did it have on their financial performance? Hospital Topics. 2010; 88: 53-60. PMid: 20494885. http://dx.doi.org/10.1080/00185861003768977

[14] Song, P. H., McCullough, J. S., Reiter, K. L. The role of non-operating income in community benefit provision by not-for-profit hospitals. Journal of Health Care Finance. 2013; 39: 59-70. PMid: 23614268.

[15] Bazzoli, G. J., Clement, J. P., Hsien, H. M. Community benefit activities of private, nonprofit hospitals. Journal of Health Politics, Policy, and Law. 2010; 35: 999-1026. PMid: 21451160. http://dx.doi.org/10.1215/03616878-2010-036

[16] Gray, B. H., Schlesinger, M. Charitable expectations of nonprofit hospitals: Lessons from Maryland. Health Affairs. 2009; 28: w809-w821. PMid: 19628474. http://dx.doi.org/10.1377/hlthaff.28.5.w809

[17] Song, P. H., McCullough, J. S., Reiter, K. L. The role of non-operating income in community benefit provision by not-for-profit hospitals. Journal of Health Care Finance. 2013; 39: 59-70. PMid: 23614268.

[18] Health Services Cost Review Commission. Maryland hospital community benefits report FY 2010. Baltimore, MD: Health Services Cost Review Commission. 2010.

[19] Gray, B. H., Schlesinger, M. Charitable expectations of nonprofit hospitals: Lessons from Maryland. Health Affairs. 2009; 28: w809-w821. PMid: 19628474. http://dx.doi.org/10.1377/hlthaff.28.5.w809

[20] Bakken, E., Kindig, D. A. Is hospital 'community benefit’ charity care? Wisconsin Medical Journal. 2012; 111: $215-219$.

[21] Rauscher, S., Vyzas, M. Assessing the validity of self-reported community benefit: Evidence from not-for-profit hospitals in California. Journal of Public Health Management and Practice. 2012; 18: 346-354. PMid: 22635189. http://dx.doi.org/10.1097/PHH.0b013e3182470578

[22] Young, G. J., Chou, C. H., Alexander, J.A., Lee, S. Y., Raver, E. Provision of community benefits by tax-exempt U.S. hospitals. New England Journal of Medicine. 2013; 368: 1519-1527. PMid: 23594004. http://dx.doi.org/10.1056/NEJMsa1210239

[23] Gray, B. H., Schlesinger, M. The accountability of nonprofit hospitals: Lessons from Maryland's community benefit reporting requirement. Inquiry. 2009; 46: 122-139. PMid: 19694387. http://dx.doi.org/10.5034/inquiryjrnl_46.02.122

[24] Magnan, S., Fisher, E., Kindig, D., Isham, G., Wood, D., Eustis M., et al. Achieving accountability for health and health care. Minneapolis, MN: State Quality Health Improvement Institute. 2012. Available from: https://www.icsi.org/_asset/qj7tk6/Commentary---Magnan.pdf

[25] Shortell, S. M., Washington, P. K., Baxter, R. J. The contributions of hospitals and health systems to community health. Annual Review of Public Health. 2009; 30: 373-383. PMid: 19296780. http://dx.doi.org/10.1146/annurev.publhealth.032008.112750

[26] Mays, G. P., Scutchfield, F. D. Improving public health system performance through multiorganizational partnerships. Preventing Chronic Disease. 2010; 7: A116. PMid: 20950523.

[27] Woulfe, J., Oliver, T. R., Zahner, S. M., Siemering, K. Q. Multisector partnerships in population health improvement. Preventing Chronic Disease. 2010; 7: A119. PMid: 20950526. 